Selahattin Akar $\odot$ Sultan Kavuncuoğlu $\odot$

Esin Yıldız Aldemir ๑

Engin Öztüregen ๑

Gülseren Arslan ๑

\title{
Comparison of Neurodevelopmental Prognosis \\ Between Late and Early Preterm Infants in \\ Preschool Period: A Prospective Cohort Study
}

Öz

Amaç: Okul öncesi dönemde geç prematürelerin nörolojik ve gelişimsel alanlarda uzun dönem prognozunu araştırmak.

Yöntem: Çalışmaya hastanemizde doğan yenidoğan yoğun bakım II.-III. düzey ünitesinde izlenen, gebelik yaşı sırasıyla $32^{0 / 7}-33^{6 / 7}$ hafta orta, $34^{0 / 7}-36^{6 / 7}$ geç ve 32 haftadan küçük erken prematüreler alındı. Araştırma sırasında olguların yaşı 37-45 ay (ort 42 \pm 3 ay) idi.

Bulgular: Çalışmaya 240 geç ve 163 erken prematüre alındı. Geç prematürelerin ortalama gebelik yaşı ve doğum ağırlığı sırasıyla $35.32 \pm 1.13$ hafta ve $1865 \pm 403$ g, erken grubun ise $30,38 \pm 1,73$ hafta ve $1253 \pm 310 \mathrm{~g}$ idi. Olgular ortalama 42 ayda değerlendirildi. Majör nörolojik sekel oranı geç prematürelerde erken prematüre grubuna göre anlamlı düşük bulundu $(p=0.001)$. Serebral palsi ve epilepsi ilk sıradaydı. Denver Gelişimsel Tarama Testi sonuçlarına göre geç prematürelerin $\% 10.8^{\prime} i$, erken grubun \%18.4'ünde gecikme saptandı, sonuç anlamlı idi ( $\left.p=0.001\right)$. Sosyoekonomik kültürel skorlamada ebeveyn eğitimi, gelir düzeyi ile gecikmeli Denver II arasında istatistiksel anlamlı ilişki bulunamadı.

Sonuç: Geç prematürelerin term algısıyla doğurtulması engellenmeli, doğanların erken prematüreler gibi uzun süreli izlemi yapılarak erken tedavi ve rehabilitasyon şansı verilmelidir.

Anahtar kelimeler: geç prematüre, erken prematüre, nörolojik-gelişimsel prognoz, majör nörolojik sekel, serebral palsi

\section{ABSTRACT}

Objective: To investigate the long term prognosis of late term prognosis in neurologic and developmental areas in preschool period.

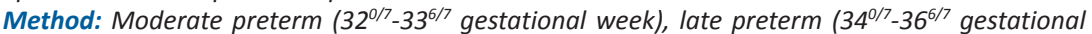
week) and early preterm (<32 gestational week) infants who were followed-up in the II-III level intensive care unit of our hospital were included in the study. Age of the subjects during the study varied between 37 and 45 months (mean $42 \pm 3$ month).

Results: A total of 240 late and 163 early preterm infants included in the study. The mean gestational age and birth weight were found as $35.32 \pm 1.13$ week and $1865 \pm 403 \mathrm{~g}$ in late preterm infants and $30.38 \pm 1.73$ weeks and $1253 \pm 310 \mathrm{~g}$ in early preterm infants, respectively. The cases were evaluated in 42 months on average. The incidence of major neurologic sequelae was significantly lower in late preterm compared to early preterm infants $(p=0.001)$. Cerebral palsy and epilepsy ranked first. According to the results of the Denver Developmental Screening Test, developmental delay was found in $10.8 \%$ of late preterm and $18.4 \%$ of early preterm infants, and the difference was significant ( $p=0.001$ ). In the socio-economic cultural scoring, no statistically significant correlation was found between parents' educational level, income level and delayed Denver II score.

Conclusion: Delivering late preterm infants with considering them term infants should be avoided if there is no definitive indication, and the delivered infants should be followed-up for a long time to give a chance for early treatment and rehabilitation.

Keywords: late preterm, early preterm, neurologic-developmental prognosis, major neurologic sequelae, cerebral palsy
Alındığı tarih: 18.01 .2020

Kabul tarihi: 20.05.2020

Yayın tarihi: 31.05 .2020

Atıf vermek için: Akar S, Kavuncuoğlu S Aldemir ES, Öztüregen E, Arslan G. Okul öncesi dönemde geç prematürelerin nörogelişimsel prognozunun erken prematürelerle karşılaştırılması: Prospektif Kohort Çalışması. IKSSTD 2020;12(2):159-68

Selahattin Akar

Bakırköy Kadın Doğum ve Çocuk Hastalıkları EAH Yenidoğan Yoğun Bakım Ünitesi İstanbul - Türkiye - selahattinakar2001@yahoo.com ORCID: 0000-0001-5915-8652

S. Kavuncuoğlu 0000-0002-6323-8994 E. Y. Aldemir 0000-0001-6141-7940 Bakırköy Kadın Doğum ve Çocuk Hastalıkları EAH Yenidoğan Yoğun Bakım Ünitesi İstanbul - Türkiye

E. Öztüregen 0000-0003-3814-5363 Bakırköy Kadın Doğum ve Çocuk Hastalıkları EAH Psikolog Istanbul - Türkiye

G. Arslan 0000-0001-5468-0476 Bakırköy Kadın Doğum ve Çocuk Hastalıkları EAH Pediatrik Nöroloji Kliniği Istanbul - Türkiye 


\section{Giriş}

Son 20-25 yılda dünyada prematüre doğumlar $\% 25$ oranında artmıştır. Bu oran erken prematürelerde (<32 hafta) \%4 orta ve geç prematürelerde (32-37 hafta) \%30 sıklıktadır. Orta ve geç prematürelerin erken prematürelere göre 7.5 kat az, term yenidoğanlara göre ise 10 kat fazla ölüm oranı bildirilmekte$\operatorname{dir}{ }^{(1,2)}$.

Acil obstetrik, fetal nedenler (preeklampsi, hipertansiyon, plasental kanama, fetal distres, intrauterin büyüme geriliği (IUBG), çoğul gebelik vs) ve term algısıyla doğurtulan orta-geç prematüreler hipoglisemi, solunum sıkıntısı, hiperbilirübinemi olmak üzere çeşitli sorunlar nedeniyle yenidoğan yoğun bakım ünitesi (YYBÜ)'ne yatırılmaktadır ${ }^{(3,4)}$. Taburculuk sonrası term algısıyla uzun süreli izlem programına alınmayan bu çocukların okul öncesi ve okul döneminde motor (kaba-ince), duyusal, öğrenme-algılama, dil, sosyal ve duygusal alanlarda yaşadıkları sorunlar eğitimcilerin ve pediatristlerin dikkatini çekmiş ve bu konuda çalışmalar başlamıştır ${ }^{(5)}$. Yapılan çalışmalarda; geç prematürelerin termlere göre $\% 36$ sıklıkta nörogelişimsel gerilik veya sekel riski taşıması nedeniyle okul öncesi hazırlık sınıfında sorunlar yaşandığı bildirilmektedir. Yazarlar bu nedenle geç prematürelerin hem okul öncesi (anasınıfı) hem de ilkokula erken gönderilmemesini önermişlerdir (4).

Erken prematürelerde nörolojik-gelişimsel alanlarda uzun dönem prognoz konusunda çok sayıda araştırma yapılmasına karşılık geç prematürelerde uzun süreli izlem ve etyolojik risk faktörleri konusunda çalışmalar kısıtlıdır ${ }^{(4,6)}$. Son yıllarda yapılan çalışmalarda geç prematürelerde saptanan nörolojik ve gelişimsel sorunların büyük oranda beyin matürasyonunun tamamlanmamasına bağlanmaktadır. Otuz dördüncü haftada beyin gelişiminin term beyin yapısının \%65'i kadar olduğu bildirilmektedir ${ }^{(7)}$. Prematüre doğumla korteksin mikrostrüktürel ve fonksiyonel bağlantılarında gelişme durur, beynin bölümleri arasındaki motor, duyusal, işitme ve dil bağlantıları kesilir. Bu çocuklardaki fonksiyonel öğrenme ve hafıza sorunlarının; anatomik, nörokimyasal, hormonal akstaki defektlere bağlı olduğu gibi, beynin reorganizasyonundaki kapasite azlığına da bağlı olduğu bildirilmektedir ${ }^{(8)}$.

Geç prematürelerin term doğan çocuklarla karşılaştırıldığı araştırmalarda; öğrenme güçlüğü, davranışsal sorunlar, dikkat eksikliği gibi sorunların daha sık görüldüğü vurgulanmaktadır. Bir başka çalışmada ise nörolojik ve gelişimsel alanda uzun dönemde ortaya çıkan sorunlarda bağımsız risk faktörlerinden erkek cinsiyet, beyaz ırk, düşük sosyoekonomik düzey, preeklampsi ve anne sütü alamamanın etkileri üzerinde durulmuştur ${ }^{(9)}$.

Bu araştırmada geç prematürelerde nörolojik ve gelişimsel alanlarda uzun dönem prognozu belirlemek ve etkileyen risk faktörlerini (perinatal, neonatal, demografik ve sosyoekonomik-kültürel) ortaya koymak amaçlandı.

\section{GEREÇ ve YÖNTEM}

Çalışma, hastanemizde 2007 yılında doğan, çalışma sırasında 36 ayını dolduran; geç prematürelerle erken prematüreler üzerinde yapıldı.

Erken prematüre(EP), orta prematüre $(\mathrm{OP})$ ve geç prematüre (GP) erken prematüre tanımında Amerika Birleşik Devletleri Ulusal Çocuk Sağlığı Enstitüsü (NICH) 2005 kriterleri kullanıldı (10). Bu sınıflamada Ballard Skorlamasına ${ }^{(11)}$ göre Gebelik yaşı (GY) 32 haftadan küçük prematüreler "erken prematüre" ve $32^{0 / 7}-33^{6 / 7}$ hafta olanlar "orta prematüre" ve $34^{0 / 7}$ $-36^{6 / 7}$ olanlar "geç prematüre" olarak adlandırılmaktadır. Çalışmamızda orta ve geç prematüreler tek grup olarak adlandırıldı. Konjenital anomalisi olan, sevk edilen, çalışmaya katılmayı reddeden ailelerin çocukları araştırmaya dahil edilmedi.

Olgulara ait bilgiler YYBÜ veri tabanından, poliklinik izlem kartlarından alındı ve kaydedildi. Perinatal risk faktörlerinden; annenin sigara içme öyküsü, erken membran rüptürü (EMR), fetal distres, doğum salonunda resüsitasyon öyküsü, 5. dakika Apgar skoru sorgulandı. Olguların demografik özelliklerinden GY, doğum ağırlığı (DA), cinsiyeti, intrauterin büyüme özellikleri, kronolojik yaşı, güncel boy ve ağırlık sorgulandı. Gebelik yaşı tayininde Ballard Skoru ${ }^{(11)}$, intrauterin büyümenin değerlerdirmesinde Ovalı ve ark. ${ }^{(12)}$ eğrileri kullanıldı. Intrauterin büyümede 10 persentil altındaki olgular Small for Gestational Age (SGA), 10-90 persentil dağılımındakiler Appropriate for Gestational Age (AGA) olarak kabul edildi. Postnatal büyümede Neyzi ve ark. ${ }^{(13)}$ Türk çocukları büyüme eğrileri kullanıldı, 3 persentilin altında (- 2 SD) olma büyüme geriliği olarak kabul edildi. Erken neonatal sorunlardan III.düzey YYBÜ'de izlem, meka- 
S. Akar ve ark., Okul Öncesi Dönemde Geç Prematürelerin Nörogelişimsel Prognozunun Erken Prematürelerle Karşılaştırılması:

Prospektif Kohort Çalışması

nik ventilasyon desteği, sepsis, respiratuvar distress sendromu (RDS), hipoglisemi, bronkopulmoner displazi (BPD), hiperbilirubinemi, intrakranial kanama (IKK), nekrotizan enterokolit (NEK), prematüre retinopatisi (ROP), konvülziyon sorgulandı. Sepsis tanımında Töllner skorlaması ${ }^{(14)}$, NEK evrelemesinde Modifiye Bell Kriterleri (15), IKK evrelemesinde Papile sınıflaması ${ }^{(16)}$, ROP tanımlaması ve sınıflamasında ise Amerikan Pediatri Akademisi $2006^{(17)}$ kriterleri kullanılmıştı. RDS tanısı klinik ve radyolojik bulgularla tanımlanmıştı. Kan şekerinin $47 \mathrm{mg} / \mathrm{dl}{ }^{(18)}$ altında olması hipoglisemi olarak değerlendirilmişti.

Çalışmaya alınan çocukların ailelerine ulaşıldı, telefonda çalışma anlatıldı, sözlü onam alındı kabul edenlere randevu verildi. Çağrılan prematüre çocuklar ve ailesi araştırmacı hekim tarafından karşılandı, çalışma anlatıldı, yazılı onam alındı.

Olguların sistemik ve nörolojik muayenesi araştırmacı hekim tarafından yapıldı. Sorunlu olgular pediatrik nörolog ile konsülte edildi. Denver II Gelişimsel Tarama Testi (DGTTII) ${ }^{(19)}$ ile gelişimsel değerlendirme gelişim uzmanı tarafından kör olarak yapıldı ve çalışmanın sonunda bulgular birleştirildi. Testin dört alanındaki işlevler çocuğa yaptırıldı, kişisel sosyal, kaba motor, ince motor, dil-işitme alanı değerlendirildi. Testin sonunda yaşına uygun alanda iki veya daha fazla gecikme durumu "Anormal Gelişim " olarak değerlendirildi. Test sonuçlarının şüpheli olduğu durumlarda çocuk 3 ay sonra tekrar değerlendirilerek sonuç normal veya gecikmeli (anormal) olarak kabul edildi.

Ailenin sosyal, ekonomik-kültürel düzey sınıflaması için skorlama yapıldı ve bulgular kaydedildi. Ailenin gelir düzeyi (asgari ücret altı ve üstü), anne babanın eğitim düzeyi (eğitimsiz ilk, orta, yüksek öğrenim), anne ve baba mesleği (işsiz, işçi, memur, serbest meslek), konut durumu, oda sayısı, evdeki toplam nüfus sorgulandı, işlendi. Ortalamanın altında kalan
(24 puan altı) sosyo-ekonomik durumu kötü, üstünde olanlar orta-iyi olarak kabul edildi. Araştırma projesi etik kurulca onaylandı. (25.06.2009/270)

\section{İstatistiksel değerlendirme}

Verilerin değerlendirilmesinde SPSS (SPSS for Windows, 16.0, SPSS Inc., Chicago, Illinois, USA) istatistik paket programı kullanıldı. Sürekli değişkenlerin normal dağılımı Kolmogrov-Smirnov testi ile değerlendirildi. Kategorik değişkenlerin analizinde ki-kare analizi, sürekli değişkenlerin analizinde normal dağılan değişkenler için student $t$ testi, normal dağılımayan değişkenler için Mann-Whitney $U$ testi uygulandı. Çok değişkenli analizde, önceki analizlerde belirlenen olası faktörler kullanılarak bağımsız prediktörler lojistik regresyon analizi kullanılarak incelendi. Model uyumu için Hosmer-Lemeshow testi kullanıldı. İstatistiksel anlamlılık \%95 güven aralığında $p<0.05$ anlamlı olarak kabul edildi.

\section{BULGULAR}

Çalışmaya 1 Ocak-31 Aralık 2007 yılında doğan araştırma tarihinde ortalama 42 aylık olan 240 geç ve 163 erken prematüre alındı. Geç prematürelerin sırasıyla ortalama GY ve DA; $35 \pm 1$ hafta ve $1865 \pm 403 \mathrm{~g}$, erken grubun ise $30 \pm 2$ hafta ve $1253 \pm 310 \mathrm{~g}$ idi (Tablo 1 ). Cinsiyet ve intrauterin büyüme oranları açısından gruplar arasında anlamlı fark bulunmadı $(p=0.654$, $p=0.543$ ve $p=0.631$ ) (Tablo 2). Perinatal özellikler ve erken neonatal sorunlar arasında gebelikte sigara kullanımı, EMR varlığı ve hiperbilirubinemi dışındaki tüm değişkenler geç prematürelerde erken prematüre grubuna göre anlamlı düşük bulundu (Tablo 3 ).

Değerlendirme tarihinde prematürelerin takvim yaşı 37-45 ay olup ortalama $42 \pm 3$ aydı. Güncel ağılıkta geç prematürelerin $\% 4.5(n=11)$ ve erken prematürelerin \%9.2 ( $n=15)$; boyda geç prematürelerin $\% 2$ $(n=15)$ ve erken grubun \%4.9 $(n=8)$ 'nin 3 persentil altında olduğu saptandı. YYBÜ'de izlem, ventilatör

Tablo 1. Olguların kronolojik yaş,doğum ağırlığı ve gebelik haftası,güncel boy ve ağırlık özellikleri.

\begin{tabular}{lcccc}
\hline & \multicolumn{2}{c}{ Geç Pramatüre $(\mathbf{n}=\mathbf{2 4 0})$} & \multicolumn{2}{c}{ Erken Pramatüre $(\mathbf{n}=\mathbf{1 6 3})$} \\
\cline { 2 - 5 } & Ortlama & Dağılım Aralığı & Ortlama & Dağılım Aralı̆̆ı \\
\hline Kronolojik yaş (ay) & $42 \pm 3$ & $39-45$ & $42 \pm 3$ & $37-45$ \\
Doğum ağırlığı (gr) & $1865 \pm 403$ & $840-3600$ & $1254 \pm 311$ & $740-2130$ \\
Gebelik yaşı (hafta) & $35 \pm 1$ & $33-37$ & $30 \pm 2$ & $26-32$ \\
Mevcut boy (cm) & $100 \pm 4$ & $92-106$ & $98 \pm 6$ & $85-106$ \\
Mevcut ağırlık (kg) & $16 \pm 1$ & $13-19$ & $15 \pm 3$ & $10-19$ \\
\hline
\end{tabular}

kg: kilogram, cm: santimetre 
Tablo 2. Olguların demografik ve gebelik haftasına göre uygunluk özelliklerinin karşılaştırılması.

\begin{tabular}{lccccc}
\hline & \multicolumn{2}{c}{$\begin{array}{c}\text { Geç Pramatüre } \\
(\mathbf{n = 2 4 0 )}\end{array}$} & \multicolumn{2}{c}{$\begin{array}{c}\text { Erken Pramatüre } \\
\text { (n=163) }\end{array}$} & \\
\cline { 2 - 6 } & $\mathbf{n}$ & $\%$ & $\mathbf{n}$ & $\%$ & $\mathbf{p}$ \\
\hline KIZ & 123 & 51.2 & 89 & 54.6 & \\
Erkek & 117 & 48.8 & 74 & 45.4 & 0.543 \\
AGA & 197 & 82.1 & 126 & 77.4 & 0.455 \\
SGA & 43 & 17.9 & 37 & 22.6 & 0.631 \\
& & & & & \\
\hline
\end{tabular}

AGA: Appropirate for Gestational Age, SGA: Small for Gestational Age

desteği, ileri evre ( $\geq$ Evre 3) IKK ve posthemorajik hidrosefali büyümeyi olumsuz etkileyen önemli risk faktörleri olarak belirlendi.

Sistemik ve nörolojik muayene sonucunda belirlenen majör nörolojik sekel sıklığı geç prematürelerde \%2.4 $(n=6)$ olup erken prematüre grubuna (\%13.9 (n=23)) göre anlamlı düşük bulundu $(p=0.001)$. En önemli sekel serebral palsi $(C P)$ olup; geç prematürelerin üçünde (\%1.2), erken grubun 10 (\%6)'unda tanımlandı ve fark anlamlı yüksek bulundu (Tablo 4). İleri evre IKK, düşük Apgar skoru, hipoglisemi öyküsü ve aşırı prematüre/aşırı düşük doğum ağırlığı olumsuz nörolojik sonuçlarda etkili risk faktörleriydi (Tablo 5). Epilepsi tanımlanan 6 olgunun 4'ü, posthemorajik hidrosefalili
Tablo 4. Olguların major nörolojik sekel durumlarının karșılaștırilması.

\begin{tabular}{lccccc}
\hline & \multicolumn{3}{c}{$\begin{array}{c}\text { Geç Pramatüre } \\
\text { (n=240) }\end{array}$} & $\begin{array}{c}\text { Erken Pramatüre } \\
\text { (n=163) }\end{array}$ & \\
\cline { 2 - 6 } Nörolojik sekel & $\mathbf{n}$ & $\%$ & $\mathbf{n}$ & $\%$ & $\mathbf{p}$ \\
\hline Spastik tetraparezi & 1 & 0.4 & 3 & 1.8 & 0.062 \\
Spastik diparezi & 2 & 0.8 & 7 & 4.2 & 0.001 \\
Epilepsi & 2 & 0.8 & 4 & 2.4 & 0.061 \\
Posthemorajik Hidrosefali & 1 & 0.4 & 5 & 3.1 & 0.042 \\
Sağıllık & - & - & 2 & 1.2 & 0.302 \\
Körlük & - & - & 2 & 1.2 & 0.302 \\
\hline Toplam & 6 & 2.4 & 23 & 13.9 & 0.001 \\
\hline
\end{tabular}

AGA: Appropirate for Gestational Age, SGA: Small for Gestational Age

EP olarak doğan çocuklardı. Geç prematürelerin ikisi epilepsi tanısı ile izlenmekteydi. Bu olgularda hipoglisemi, sepsis, IKK, hidrosefali ve menenjit gibi risk faktörlerinden en az birinin mevcut olduğu görüldü. Sağırlık ve körlük sadece erken prematüre grubundaki olgularda ve $\% 1.2$ oranında belirlendi.

Denver Gelişimsel Tarama Testi II ile GP grupta \%10.8 ve erken prematürde \%18.4 sorun saptandı ve gruplar arasındaki fark anlamlı bulundu $(p=0.001)$. Her iki grupta kişisel sosyal, kaba motor gelişim alanında gerilik oranları benzerdi ( $p>0.05$ ). Ancak erken prematürelerde dil ve ince motor alandaki gecikme GP

Tablo 3. Olguların perinatal ve neonatal dönemdeki morbidite ve risk faktörlerinin karşılaştırılması.

\begin{tabular}{|c|c|c|c|c|c|}
\hline \multirow[b]{2}{*}{ Değişkenler } & \multicolumn{2}{|c|}{ Geç Pramatüre $(n=240)$} & \multicolumn{2}{|c|}{ Erken Pramatüre $(n=163)$} & \multirow[b]{2}{*}{$\mathbf{p}$} \\
\hline & $\mathbf{n}$ & $\%$ & $\mathbf{n}$ & $\%$ & \\
\hline Gebelikte Sigara Kullanımı & 47 & 19.5 & 33 & 22.6 & 0.371 \\
\hline EMR & 32 & 13.3 & 34 & 20.8 & 0.580 \\
\hline Antenatal Steroid & 33 & 13.7 & 45 & 27.6 & 0.001 \\
\hline Doğum salonunda resüsitasyon & 17 & 7.1 & 34 & 20.9 & 0.001 \\
\hline 5. dk. Apgar skoru <6 & 20 & 8.3 & 26 & 15.9 & 0.001 \\
\hline Anemi & 76 & 31.6 & 82 & 50.3 & 0.001 \\
\hline Hiperbilirubinemi & 50 & 20.8 & 45 & 27.6 & 0.554 \\
\hline RDS & 37 & 15.4 & 41 & 25.1 & 0.011 \\
\hline Sepsis & 35 & 14.5 & 38 & 23.3 & 0.020 \\
\hline Hipoglisemi & 26 & 10.8 & 25 & 15.3 & 0.001 \\
\hline Menenjit & 16 & 6.6 & 23 & 14.1 & 0.003 \\
\hline NEK & 13 & 5.4 & 15 & 9.2 & 0.001 \\
\hline BPD & 6 & 2.5 & 16 & 9.8 & 0.001 \\
\hline Konvülziyon & 7 & 2.9 & 10 & 6.1 & 0.001 \\
\hline IKK >Evre III & 2 & 0.8 & 9 & 5.5 & 0.001 \\
\hline Posthemorajik hidrosefali & 1 & 0.4 & 5 & 3.1 & 0.042 \\
\hline$>$ Evre III ROP & - & - & 5 & 3.06 & 0.001 \\
\hline
\end{tabular}

EMR: Erken membran rüptürü, RDS: Respiratuvar distres sendromu, BPD: Bronkopulmoner displazi,

NEK: Nekrotizan enterekolit, IKK: Intrakranial kanama, ROP: Prematüre Retinopatisi 
Tablo 5. Serebral palsili olguların özellikleri.

\begin{tabular}{|c|c|c|c|c|c|c|c|c|c|c|c|}
\hline Olgu & DA & GY & $\begin{array}{l}\text { 5.DAK } \\
\text { Apgar }\end{array}$ & $\begin{array}{l}\text { CP } \\
\text { Tipi }\end{array}$ & $>\underset{\text { IKK }}{\text { Evre III }}$ & Hidrosefali & Menenjit & Sepsis & Hipoglisemi & $\begin{array}{c}\text { Anormal } \\
\text { DGTT II }\end{array}$ & $\begin{array}{c}\text { Rehabilitasyon } \\
\text { başlangıç zamanı (ay) }\end{array}$ \\
\hline 1 & 1210 & 32 & 7 & SD & Evre III & - & - & + & + & + & 9 \\
\hline 2 & 1190 & 32 & 6 & SD & - & - & - & + & + & + & 12 \\
\hline 3 & 970 & 28 & 7 & ST & Evre III & + & - & - & - & + & 12 \\
\hline 4 & 1010 & 29 & 5 & ST & Evre III & + & - & - & - & + & 8 \\
\hline 5 & 960 & 28 & 6 & SD & - & - & - & + & + & + & 18 \\
\hline 6 & 980 & 28 & 7 & SD & Evre III & - & - & - & - & + & 9 \\
\hline 7 & 890 & 29 & 5 & ST & Evre IV & + & - & - & - & + & 8 \\
\hline 8 & 1100 & 28 & 4 & SD & - & - & - & + & + & + & 15 \\
\hline 9 & 850 & 27 & 5 & SD & Evre IV & + & - & + & + & + & 12 \\
\hline 10 & 875 & 27 & 4 & SD & Evre III & + & - & + & + & + & 24 \\
\hline 11 & 1470 & 35 & 5 & ST & Evre III & + & - & - & - & + & 12 \\
\hline 12 & 1240 & 33 & 5 & SD & Evre III & - & + & + & + & + & 9 \\
\hline 13 & 1310 & 34 & 7 & SD & - & - & + & + & + & + & 9 \\
\hline
\end{tabular}

DA: Doğum ağırlığı (gram), GY: Gebelik yaşı, CP: Cerebral Palsi, SD: Spastik dipleji, ST: Spastik tetrapleji, iKK: Intrakranial kanama.

Tablo 6. Geç ve Erken Prematürelerin DENVER II Gelişim Tarama Testi sonuçlarının değerlendirilmesi.

\begin{tabular}{|c|c|c|c|c|c|c|c|c|c|}
\hline & \multicolumn{4}{|c|}{ Geç Pramatüre (n=240) } & \multicolumn{4}{|c|}{ Erken Pramatüre $(n=163)$} & \multirow[b]{3}{*}{$\mathbf{P}$} \\
\hline & \multicolumn{2}{|c|}{ Normal } & \multicolumn{2}{|c|}{ Anormal } & \multicolumn{2}{|c|}{ Normal } & \multicolumn{2}{|c|}{ Anormal } & \\
\hline & $\mathbf{n}$ & $\%$ & $\mathbf{n}$ & $\%$ & $\mathbf{n}$ & $\%$ & $\mathbf{n}$ & $\%$ & \\
\hline Genel & 214 & 89.2 & 26 & 10.8 & 133 & 81.6 & 30 & 18.4 & 0.001 \\
\hline Kişisel-Sosyal Gelişim & 232 & 95.1 & 8 & 4.9 & 149 & 91.5 & 14 & 8.5 & 0.231 \\
\hline Kaba Motor Gelişimi & 237 & 98.8 & 3 & 1.2 & 153 & 93.9 & 10 & 6.1 & 0.061 \\
\hline Dil Gelişimi & 230 & 95.9 & 10 & 4.1 & 133 & 81.6 & 30 & 18.4 & 0.001 \\
\hline İnce Motor Gelişimi & 228 & 92.7 & 12 & 7.3 & 135 & 82.9 & 28 & 17.1 & 0.001 \\
\hline
\end{tabular}

Tablo 7. Anormal DGTT II'nin perinatal, neonatal risk faktörleriyle ilişkisi.

\begin{tabular}{lcccc}
\hline Parametre & OR & 95\% C.I. for OR & P \\
\hline Doğum salonunda resüsitasyon & 3.645 & 1.703 & 5.008 & 0.001 \\
Apgar 5. dk<6 & 4.534 & 1.525 & 4.705 & 0.015 \\
BPD & 2.101 & 1.436 & 3.694 & 0.005 \\
Hipoglisemi & 3.316 & 1.983 & 4.583 & 0.002 \\
Sepsis & 0.847 & 0.762 & 1.145 & 0.228 \\
IKK > Evre 3 & 5.040 & 1.682 & 6.957 & 0.001 \\
\hline
\end{tabular}

Lojistik regresyon analizi, BPD: Bronkopulmoner Displazi, iKK: intrakranial Kanama

grubuna göre anlamlı düşük bulundu $(p=0.001)$ (Tablo 6). Denver II Gelişimsel Tarama Testi'nde anormal sonucu doğum salonunda resüsitasyonun 3.6 kat, 5.dakika düşük Apgar skorunun 4.5 kat, BPD’nin 2 kat, ileri evre IKK'nın 5 kat ve hipogliseminin 3.3 kat arttırdığı saptandı (Tablo 7).

Geç prematürelerin \%4.6'sının ve erken grubun \%7.4'ünün düşük sosyoekonomik ve kültürel düzey- de olduğu görüldü. Geç prematüre grupta annelerin \%46.7'si ve babaların \%51.2'sinin eğitim düzeyi ilköğretim iken bu oran EP grupta sırasıyla \%40.4 ve \%54.6 idi (Tablo 8). Gruplar arasında gecikmeli DGTT II ile sosyal-kültürel ve ekonomik değişkenler açısından anlamlı fark bulunmadı ( $p>0.05$ ), (Tablo 9).

\section{TARTIŞMA}

Bu araştırmada amacımız; geç prematürelerin okul öncesi dönemdeki nörolojik ve gelişimsel prognozunu incelemek; perinatal, neonatal ve sosyodemografik faktörlerin etkisini değerlendirmekti. Literatürde geç prematürelerin uzun süreli izleminde term gruplarla karşılaştırmalı çalışmaların sayısı kısıtlıdır, özellikle erken prematürelerle karşılaştırılan ve perinatal, neonatal risk faktörlerini irdeleyen çalışmaya bildiğimiz kadarıyla rastlanmamıştır.

Gerek acil obstetrik ve/veya fetal nedenlerle, gerekse term algısı ile doğurtulan geç prematürelerin uzun 
Tablo 8. Geç ve Erken Prematürelerin Sosyoekonomik-Kültürel özelliklerinin değerlendirilmesi.

\begin{tabular}{|c|c|c|c|}
\hline & $\begin{array}{l}\text { Geç Pramatüre } \\
\qquad(n=240)\end{array}$ & $\begin{array}{l}\text { Erken Pramatüre } \\
(n=163)\end{array}$ & $\mathbf{p}$ \\
\hline \multicolumn{4}{|l|}{ Anne mesleği } \\
\hline Ev Hanımı, n \% & $196(\% 81.6)$ & $128(\% 78.6)$ & 0.486 \\
\hline İşçi/Memur, n \% & $25(\% 10.4)$ & $18(\% 11)$ & 0.162 \\
\hline Serbest, n \% & $13(\% 5.4)$ & $10(\% 6.1)$ & 0.257 \\
\hline Üst düzey, n \% & $6(\% 2.6)$ & $7(\% 4.3)$ & 0.746 \\
\hline \multicolumn{4}{|l|}{ Baba mesleği } \\
\hline İşsiz, n \% & 26 (\%10.9) & $15(\% 9.2)$ & 0.469 \\
\hline İşçi/Memur, n \% & $104(\% 43.3)$ & $75(\% 46)$ & 0.118 \\
\hline Serbest, n \% & $98(\% 40.8)$ & $70(\% 43)$ & 0.523 \\
\hline Üst düzey, n \% & $12(\% 5)$ & $3(\% 1.8)$ & 0.154 \\
\hline \multicolumn{4}{|l|}{ Akrabalık } \\
\hline 1.derece, n \% & $32(\% 13.3)$ & $18(\% 11)$ & 0.203 \\
\hline 2.derece, $\mathrm{n} \%$ & $9(\% 3.7)$ & $6(\% 3.7)$ & 0.159 \\
\hline Uzaktan, n \% & $55(\% 23)$ & $29(\% 17.8)$ & 0.078 \\
\hline Yok, n \% & $144(\% 60)$ & $110(\% 67.5)$ & 0.457 \\
\hline \multicolumn{4}{|l|}{ Gelir düzeyi } \\
\hline Asgari ücret, n \% & $55(\% 23)$ & $34(\% 20.8)$ & 0.912 \\
\hline Asgari Ücret altı, n \% & $135(\% 56.2)$ & $88(\% 54)$ & 0.153 \\
\hline Asgari ücret üstü, n \% & $50(\% 20.8)$ & $41(\% 25.2)$ & 0.280 \\
\hline \multicolumn{4}{|l|}{ Anne Eğitim Düzeyi } \\
\hline Eğitimsiz, n \% & $9(\% 3.8)$ & 7 (\%4.3) & 0.121 \\
\hline İlköğretim, n \% & $112(\% 46.7)$ & $66(\% 40.4)$ & 0.815 \\
\hline Lise, $\mathrm{n} \%$ & $79(\% 32.9)$ & 57 (\%35) & 0.917 \\
\hline Üniversite, n \% & $40(\% 16.6)$ & $33(\% 20.3)$ & 0.065 \\
\hline \multicolumn{4}{|l|}{ Baba eğitim düzeyi } \\
\hline Eğitimsiz, n \% & $5(\% 2)$ & $8(\% 5)$ & 0.384 \\
\hline İlköğretim, n \% & $123(\% 51.2)$ & $89(\% 54.6)$ & 0.535 \\
\hline Lise, $\mathrm{n} \%$ & $85(\% 35.5)$ & $49(\% 30)$ & 0.069 \\
\hline Üniversite, n \% & 27 (\%11.3) & $17(\% 10.4)$ & 0.433 \\
\hline Sosyo ekonomik Skor & $25 \pm 12$ & $26 \pm 18$ & 0.139 \\
\hline
\end{tabular}

süreli izleminde yaşadığı sorunlar, matürasyonu tamamlanmamış beyin ve sinir sistemi yapısıyla ilgili olup özellikle okul öncesi ve okul döneminde davranış, algılama, öğrenme, konuşma alanındaki bozukluklar pediatristlerin ve eğitimcilerin dikkatini çekmiştir ${ }^{(6)}$. Perinatal ve neonatal risk faktörlerinin uzun dönem gelişimsel sürece olumsuz etkisi sorgulanırken, Kinney $\mathrm{HC}^{(7)}$ çalışmasında geç prematürelerin beyin yapısının immatür olduğunu 34. gebelik haftasında beyin ağırlığının term bebek beyninin $\% 65^{\prime} i$ kadar olduğunu bildirmiş, matürasyonun prognoza etkisini vurgulamıştır. Araştırmamızda genel hatları ile geç prematürelerin 6 (\%2.4)'sı, erken prematürelerin 23 (\%13.9)'ünde majör nörolojik sekel tanımlandı. Değerlendirmede anormal DGTT II sıklığı GP grupta 26 (\%10.8) ve erken prematürelerde 30 (\%18.4) idi. Dil gelişiminde ve ince motor alanda gerilik erken prematürelerde anlamlı yüksek saptanırken ( $p=0.001)$, buna karşılık kaba motor ve kişisel sosyal alanda skorlar her iki grupta benzer bulundu (sırasıyla $p=0.231$ ve $p=0.061$ ).

Benjamin Morse ve ark. ${ }^{(4)}$ anaokuluna giden sağlıklı geç prematürelerle termleri karşılaştırdıkları çalışmada nörolojik-gelişimsel geriliği \%19 sıklıkta rapor etmişlerdir. Yazarlar geç prematürelerde term gruba göre annede sigara öyküsünün, komplikasyonlu gebelik ve doğumun, ventilatör tedavinin etyolojik risk faktörleri olduğunu vurgulamışlardır. Yine aynı çalışmada okul öncesi döneme vurgu yapılarak 36 ay ve 4 yaştaki gerilik sıklığını sırasıyla $\% 13$ ve $\% 10$ ola-

Tablo 7. Geç ve erken prematürelerin DENVER II Gelişim Tarama Testi ve Sosyoekonomik-Kültürel Düzeyin Karşılaştırılması.

\begin{tabular}{|c|c|c|c|c|c|c|c|c|c|}
\hline & \multicolumn{4}{|c|}{ Geç Pramatüre (n=240) } & \multicolumn{4}{|c|}{ Erken Pramatüre (n=163) } & \multirow[b]{3}{*}{$\mathbf{P}$} \\
\hline & \multicolumn{2}{|c|}{ Normal } & \multicolumn{2}{|c|}{ Anormal } & \multicolumn{2}{|c|}{ Normal } & \multicolumn{2}{|c|}{ Anormal } & \\
\hline & $\mathbf{n}$ & $\%$ & $\mathbf{n}$ & $\%$ & $\mathbf{n}$ & $\%$ & $\mathbf{n}$ & $\%$ & \\
\hline \multicolumn{10}{|l|}{ Baba Eğitim Düzeyi } \\
\hline Eğitimsiz & 4 & $\% 1.7$ & 1 & $\% 0.4$ & 4 & $\% 2.5$ & 4 & $\% 2.5$ & 0.268 \\
\hline Illköğretim & 115 & $\% 48.0$ & 8 & $\% 3.3$ & 74 & $\% 45.3$ & 15 & $\% 9.2$ & 0.167 \\
\hline Lise & 73 & $\% 30.4$ & 12 & $\% 5$ & 44 & $\% 27.0$ & 5 & $\% 3.1$ & 0.371 \\
\hline Üniversite & 22 & $\% 9.1$ & 5 & $\% 2.1$ & 11 & $\% 6.7$ & 6 & $\% 3.7$ & 0.258 \\
\hline \multicolumn{10}{|l|}{ Anne Eğitim Düzeyi } \\
\hline Eğitimsiz & 6 & $\% 2.5$ & 3 & $\% 1.3$ & 4 & $\% 2.4$ & 3 & $\% 1.8$ & 0.980 \\
\hline ilköğretim & 96 & $\% 40$ & 16 & $\% 6.6$ & 57 & $\% 35.0$ & 9 & $\% 5.6$ & 0.784 \\
\hline Lise & 77 & $\% 32.1$ & 2 & $\% 0.8$ & 46 & $\% 28.2$ & 11 & $\% 6.7$ & 0.504 \\
\hline Üniversite & 35 & \%14.6 & 5 & $\% 2.1$ & 26 & \%16.0 & 7 & $\% 4.3$ & 0.231 \\
\hline \multicolumn{10}{|l|}{ Gelir Düzeyi } \\
\hline Asgari ücret & 50 & $\% 20.8$ & 5 & $\% 2.1$ & 26 & $\% 16.0$ & 8 & $\% 4.9$ & 0.673 \\
\hline Asgari ücret altı & 121 & $\% 50.4$ & 14 & $\% 5.8$ & 72 & $\% 44.1$ & 16 & $\% 9.8$ & 0.583 \\
\hline Asgari ücret üstü & 43 & $\% 18.0$ & 7 & $\% 2.9$ & 35 & $\% 21.5$ & 6 & $\% 3.6$ & 0.342 \\
\hline \multicolumn{10}{|l|}{ Sosyoekonomik Skor } \\
\hline Kötü & 13 & $\% 5.4$ & 11 & $\% 4.6$ & 8 & $\% 4.9$ & 12 & $\% 7.4$ & 0.524 \\
\hline Normal-iyi & 201 & $\% 83.8$ & 15 & $\% 6.2$ & 125 & $\% 76.7$ & 18 & $\% 11.0$ & 0.435 \\
\hline
\end{tabular}


S. Akar ve ark., Okul Öncesi Dönemde Geç Prematürelerin Nörogelişimsel Prognozunun Erken Prematürelerle Karşılaştırılması:

Prospektif Kohort Çalışması

rak bildirmişlerdir.

Bizim çalışmamızda; benzer yaş grubundaki (ort. 42 ay) geç ve erken prematürelerin perinatal risk faktörleri incelendiğinde; gebelikte sigara öyküsü, EMR, antenatal steroid, doğum odasında resusitasyonun nörolojik-gelişimsel süreç üzerine etkisi sorgulandı. Yapılan araştırmalardan farklı olarak ${ }^{(20,21)}$ çalışmamızda gebelikte sigara kullanımı, EMR ve antenatal steroid kullanımı ile uzun dönem nörolojik ve gelişimsel sonuçlar arasında ilişki bulunmadı (Lojistic regresyon analizi, $95 \mathrm{Cl}$ for $\mathrm{OR} \mathrm{p}>0.05$ ).

Araştırmamızda geç prematürelerin $\% 7.1^{\prime} i$ erken prematürelerin \%20.9'u doğum salonunda resusite edilmişti ve 5 . $\mathrm{dk}^{\prime}$ da düşük Apgar skoru sırasıyla $\% 8.3$ ve \%15.9 sıklıktaydı. Her iki grup bu veriler ışı̆ıında değerlendirildiğinde gecikmeli DGTT II sıklığını doğum salonunda resüsitasyonun 3.6 kat, düşük Apgar skorunun 4.5 kat arttırdığı saptandı. Her iki grupta kişisel sosyal gelişim ve kaba motor gelişimi alanlarında gerilik mevcuttu ancak gruplar arasındaki fark anlamIı bulunmadı. Buna karşılık ince motor gelişim ve dil gelişimi alanında gerilik erken prematürelerde yüksekti ve fark anlamlıydı ve bulgular Göçer ve ark. ${ }^{(20)}$ ile Koç ve ark. ${ }^{(23)}$ bulgularına benzerdi.

Jennifer ve ark. ${ }^{(24)}$ YYBÜ'de yatan ve yatmayan geç prematüreleri 3 yaşında Bayley III testi ile değerlendirdiği çalışmalarında her iki grupta dil, bilişsel ve motor alanlarda fark olmadığını bildirmiştir. Yazarlar bu bebeklerin annelerinde preeklampsi, kanama gibi sorunlar nedeniyle doğuma alındığını, resusitasyon gereksinimi olduğunu yoğun bakımda yatanlarda özellikle SGA oranının yüksek olduğunu vurgulamışlardır. Jong ve ark. ${ }^{(25)} 2015$ yılında yaptıkları çalışmada 24 aylık geç prematüreleri term grupla Bayley III testi ile karşılaştırdıklarında olguların algılama, alıcı dil, iletişim ve motor alanlarda sorunlu olduğunu rapor etmişlerdir.

Uzun dönem sonuçlara cinsiyetin etkisi sorgulandığında araştırmamızda Claudhari ve ark. ${ }^{(26)}$ çalışmasına benzer bulundu. Her iki grupta erkek prematürelerde kızlara göre gecikmeli DGTT II sıklığı anlamlı bulundu. Samantha Johnson ve ark. ${ }^{(9)}$ saptanan gelişimsel gecikmede erkek cinsiyet ve beyaz ırkın olumsuz etkilerine vurgu yapmıştır. Göçer ve ark. ${ }^{(22)}$ erken prematüreleri 36. ayda değerlendirdiği araştırmada; gecikmeli DGTT II ile erkek cinsiyet arasında anlamlı ilişki olduğunu rapor etmiştir.
vanBaar ve ark. ${ }^{(27)}$ geç prematürelerde davranışsal sorunların daha sık olduğuna dikkat çekerek literatürde erken neonatal sorunların etkisi konusunda araştırmaların yetersiz olduğunu vurgulamışlardır. Biz de bu çalışmamızda erken neonatal sorunların nörolojik-gelişimsel sonuçlar üzerine etkilerini sorguladık. Nörolojik-gelişimsel değerlendirmede DGTT II kullanmamız bu çalışmanın eleştiriye açık yanıdır, çünkü DGTT II testinin özellikle erken prematürelerin değerlendirilmesinde yetersiz olduğu, ancak tarama testi olarak kullanılabileceği bildirilmektedir. Araştırmamızda olgu sayımızın fazla olması, diğer testler için olanaklarımızın kısıtılığı ve DGTT II'nin Türk çocuklarına adapte edilmiş bir test olması nedeniyle kullanıldı. Hipoglisemi uzun süreli izlemde nörolojik-gelişimsel alanları olumsuz etkilemektedir ${ }^{(28,29)}$. Çalışmamızda hipogliseminin özellikle erken prematürelerde sık olduğu, anormal DGTT II ile anlamlı ilişki gösterdiği saptandı.

Neonatal sepsis özellikle menenjit ile komplike olduğunda \%20-100 sıklıkta ağır nörolojik-gelişimsel geriliğe neden olmaktadır ${ }^{(30)}$. Göçer ve ark. ${ }^{(22)}$ çalışmasında sepsis geçiren 3 yaştaki erken prematürelerin DGTT II skorlarında belirgin gecikme bulmuşlardır. Buna karşıık hastalığın uzun dönem sonuçlara etkisiz olduğuna dair çalışmalar yayınlanmıştır ${ }^{(21)}$. Koç ve ark. ${ }^{(23)}$ ortalama 87 aylık erken prematüre çocukların okul başarısını araştırdığı çalışmasında neonatal sepsisin WiSC-AR zeka puanını etkilemediğini rapor etmişlerdir. Araştırmamızda hem geç hem erken prematürelerde sepsis öyküsü gecikmeli DGTT II ile istatistiksel anlamlı ilişkili bulunmuştur.

Intrakranial kanama gebelik haftası küçük prematürelerin en önemli morbiditesi olup uzun süreli izlemde sekel oranı yüksektir. Özellikle bilişsel ve motor alanda ciddi geriliğe neden olmaktadır ${ }^{(31,32)}$. Piecuch ve ark. ${ }^{(33)} 1000$ gr altındaki prematürelerin 55 aylıkken değerlendirilmesinde sekel oranını \%39 saptamış, İKK derecesi, BPD ve PVL'nin prognoza etkisine dikkat çekmiştir. Sherlock ve ark. ${ }^{(34)}$ erken prematüreleri sekiz yaşında değerlendirdiği çalışmada serebral palsi ve kötü motor performansın ileri evre İKK ile ilişkisini vurgulamıştır. Göçer ve ark. ${ }^{(22)}$ benzer grupta Evre III üzeri IKK'lı olguların anormal DGTT II ile korelasyon gösterdiğini vurgulamışlardır. Çalışmamızda IKK tanımlanan geç prematürelerde gecikmeli DGTT |l sıklığı \%10, erken prematürelerde $\% 12$ olarak bulunmuştur. Her iki grubun dil ve ince motor alanda 
geriliği dikkati çekmektedir. Evre III ve üzeri IKK geç prematürelerde iki, erken grupta 9 olguda saptanırken, çocukların tamamında ve tüm alanlarda DGTT II gecikmeli bulunmuştur.

Serebral palsi majör nörolojik sekellerden ilk sıradaki morbidite olup sıklığı literatürde gelişmiş ülkelerde 1000 'de 2.1 iken riskli gruplarda ise \%10'a kadar varabilmektedir ${ }^{(35)}$. Vries ve ark. ${ }^{(36)}$ erken prematürelerde sıklığı \%5, 33-36 gebelik haftasında \%6 olarak rapor etmişlerdir. Göçer ve ark. ${ }^{(22)} 32$ haftadan küçük prematürelerde CP sıklığını \%8.5 olarak bildirmişlerdir. Petrini ve ark. ${ }^{(37)}$ geç prematürelerde gebelik yaşı azaldıkça serebral palsi ve mental retardasyon riskinin arttığını rapor etmişlerdir. Çalışmamızda geç prematürelerden 3 çocukta ve erken prematürelerin 10 'unda serebral palsi tanımlandı. Olguların risk faktörleri irdelendiğinde; geç prematürelerde düşük Apgar skoru, ileri evre IKK, posthemorajik hidrosefali, sepsis, menenjit ve hipoglisemi saptanırken; erken grupta sepsis, hipoglisemi, ileri evre İKK ve aşırı düşük doğum ağırııkı olma dikkati çekiyordu (Tablo 5).

Posthemorajik hidrosefali ileri evre IKK'nın önemli bir komplikasyonudur. Çalışmamızda 11 ileri evre iKK'lı olguların altısında (\%54.5) hidrosefali gelişti (GP1,EP5). Volpe (38) hidrosefalili olgularda \%80 motor, $\% 53$ bilişsel sorun, $\% 10$ normal gelişim olabileceğini bildirmiştir. Hidrosefali gelişen tüm olgularımız serabral palsi tanısı aldı ve DGTT II tüm alanlarda gecikmeliydi.

Işitme kaybı term yenidoğanlarda $1 / 800$, prematürelerde 43/1000 sıklıkta bildirilmiştir ${ }^{(39)}$. Bir başka çalışmada; 20500 canlı doğumda 1.5/1000 riskli yenidoğanlarda 21/1000 olarak rapor edilmiştir; işitme kaybı aile öyküsü, akraba evliliği, mekanik ventilasyon, kan değişimi, konvülziyon, menenjit, TORCH enfeksiyonu ile ilişkili bulunmuştur ${ }^{(40)}$. Çalışmamızda geç prematürelerde sağırlık saptanmazken erken grupta 2 olguda sağırlık 15 olguda hafif işitme azlığı tanımlanmıştır. En önemli risk faktörleri olarak $\geq$ evre III IKK, sepsis, menenjit saptandı. Sonuçlarımız Robertson ve ark. ${ }^{(41)}$ Tomasik ve ark. ${ }^{(42)}$ çalışmasındaki risk faktörlerine benzer bulundu.

Neonatal dönemdeki subtle konvülziyonların postneonatal dönemde \%8-9 sıklıkta epilepsi geliştirdiği rapor edilmiştir ${ }^{(43)}$. Epilepsi uzun süreli izlemde önemli sekellerden biridir. Çalışmamızda geç prematürelerden $2(\% 0.8)$ erken gruptan $4(\% 2.4)$ olgu epilepsi tanısıyla pediatrik nörolojide izlenmektedir, aynı zamanda serebral palsili bu olgular rehabilitasyon programına devam etmektedir.

Literatürde sosyal, ekonomik ve kültürel düzeyin uzun dönemde prematüre çocukların somatik ve nörogelişimsel prognozu üzerine etkisini araştıran birçok çalışma bulunmaktadır. Epidemiyolojik bir çalışmada; büyüme ve gelişme üzerine en etkili faktörler olarak prematürenin yaşadığı ortam, bakım kalitesi, multidisipliner izlem, anne sütü, annenin ruhsal ve bedensel sorunları, düşük eğitim düzeyi, anne-bebek bağlanma yetersizliği beslenme sorunları ve rehospitalizasyon vurgulanmıştır ${ }^{(44,45)}$. Vohr ve ark. ${ }^{(46)}$ sosyodemografik etkenlerin özellikle 5 yaştan sonra önem kazandığını ve iyi sosyoekonomik düzeye sahip prematürelerde gelişimin olumlu etkilendiğini bildirmişlerdir. Morris BH ve ark. ${ }^{(47)}$ erken prematürelerin ilk yılda sık hastaneye yatırıldığını bu durumun düşük sosyoekonomik düzeyle ilişkisi olduğunu belirtmişlerdir. EPIPAGE çalışmasında (48) iki yaşındaki erken prematürelerin majör nörolojik sekellerinin sosyokültürel ekonomik düzeyle ilişkisi vurgulanmıştır ${ }^{(45)}$. Özsoy Koç ve ark. ${ }^{(23)}$ okul çağındaki erken prematüreleri değerlendirdiği çalışmasında; düşük sosyoekonomik düzeyle <85 WiSCAR zekâ puanı arasında ilişki olduğunu ve özellikle baba eğitimi ve mesleğinin anlamlı düzeyde etkisi olduğuna dikkat çekmişlerdir. Göçer ve ark. ${ }^{(22)}$ çalışmasında ise üç yaştaki erken prematürelerde nörolojik-gelişimsel alanlarda uzun dönem prognozla sosyoekonomik düzey arasında ilişki bulunamamıştır. Çalışmamızda da sosyoekonomik kültürel düzey skorlamasında her iki grubun ortalama puanları benzerdi, fark saptanmadı. Sosyoekonomik-kültürel düzeyler arasında fark olmaması ve DGTT II skorlarının anlamlı farklı etkilenmemesi; ailelelerin yapısının büyük oranda benzerliği yanında, her düzeydeki ebeveynin çocuklarına desteğinin devam ettiğini, izlem ve rehabilitasyonda çaba harcadıklarını göstermektedir. Ayrıca her iki gruptaki ailelerin sosyal güvencelerinin olmasının da izlem ve rehabilitasyonda fark oluşturmadığı düşünülmüştür.

Geç prematürelerin sorunlarının okul öncesi ve okul yaşında ortaya çıktığı, bunların davranış sorunları ve okul başarısızlığı olarak rapor edildiği bilinmektedir. Geç, orta prematürelerin term grupla karşılaştırıldığı derlemede 17 çalışma irdelenmiş, 5-10 yaştaki prematürelerin term doğanlardan 1.3-2.8 kat özel eğitim gereksinimi olduğu, sözel ve sayısal alanda başarısız 
S. Akar ve ark., Okul Öncesi Dönemde Geç Prematürelerin Nörogelişimsel Prognozunun Erken Prematürelerle Karşılaştırılması:

Prospektif Kohort Çalışması

olduğu ve 1.3-2.2 kat sınıf tekrarı gerektiği bildirilmiş (6). Mental gerilik sıklığının 1.3-1.9 kat yüksek olduğu vurgulanmıştır ${ }^{(37,49)}$. Bahsedilen derlemede ${ }^{(6)}$ geç ve orta prematürelerde term doğanlara göre otizm ve hiperaktivite sıklığının yüksek olduğu bildirilmiştir. Araştırmamızda geç prematürelerin \%10.8 erken prematürelerin \%18.4'ü gecikmeli DGTT II skoruna sahipti, bunun yanında 13 motor defisit 2 körlük, 2 sağırlık olmak üzere motor ve duyusal alanda sorun yaşıyordu. Olgular izlem sırasında rehabilitasyon programına alındı.

Sonuç olarak prematürelerin uzun süreli izlemi bir halk sağıı̆ı hizmetidir. Çok düşük doğum ağırlıklı prematüreler üzerine yoğunlaşan birçok izlem çalışmaları literatürde yerini alırken, geç prematürelerin okul öncesi, okul ve adölesan dönemde ortaya çıkan nörolojik-gelişimsel sorunları 2000'li yılların başında araştırılmaya başlanmıştır. Biz de bu çalışmamızda 2007 yılında doğan okul öncesi dönemdeki geç ve erken prematürelerin perinatal, neonatal dönem sorunlarından nasıl etkilendiğini ortaya koyduk. Gebelik haftasının intrauterin gelişmede anahtar rol oynadığını vurgulayarak term algısı ile geç prematürelerin doğurtulmamasını, zorunlu nedenlerle doğanların diğer prematüreler gibi izlenmesinin olası sekelleri önleyeceği kanısındayız.

Etik Kurul Onayı: Bakırköy Kadın Doğum ve Çocuk Hastalıkları Eğitim ve Araştırma Hastanesi Klinik Araştırma Etik Kurulu tarafından onaylandı. (25.06.2009/-270 etik onay numarası)

Çıkar Çatışması: Herhangi bir çıkar çatışması yoktur.

Finansal Destek: Finansal destek yoktur.

Hasta Onamı: Tüm hastaların yazılı onamı alındı.

Ethics Committee Approval: Approved by Bakırkoy Women's and Children's Diseases Education and Research Hospital Clinical Research Ethics Committee. (25.06.2009-270 ethical approval number).

Conflict of Interest: No conflict.

Funding: No funding.

Informed Consent: Written informed consent was obtained from all patients.

\section{KAYNAKLAR}

1. Martin JA, Hamilton BE, Suttan PD. Births final data for 2007 NatIVital Stat Rep. 2010;58:1-85.

2. Mathews TJ, MacDorman MF. Infant mortality statics from the 2005 Period Linked Birth/Infant Death Data SetNatIVital Stat Rep. 2008;57:1-32.
3. Kalyoncu Ö, Aygün C, Çetinoğlu E, Küçüködük Ş. Neonatal Morbidity and mortality of late preterm babies. J Maternal-Fetal and Neonatal Med. 2010;23(7):607-12. https:// doi: 10.1080/14767050903229622

4. Morse SB, Hao Zheng, Tang Y, Roth J. Early School-Age Outcomes of Late Preterm Infants Pediatrics. 2009;123(4):622-9. https:// doi: 10.1542/peds.2008-1405

5. Woythaler MA, McCormick MC and Smith VC. Late preterm infants have worse 24 month neurodevelopmental outcomes than term infants. Pediatrics. 2011;127(3):622-9.

https:// doi: doi: 10.1542/peds.2009-3598

6. de Jong M, Verhoeven M, Van Baar AL. School outcome, Cognitive functioning and behavior problems in moderade and late preterm children and adults: A Review. Semin Fetal Neonatal Med. 2012;17(3):163-9. https:// doi: 10.1016/j.siny.2012.02.003

7. Kinney HC. The Near Term (Late Preterm) Human Brain and Risk for Periventricular Leukomalacia: A Review Semin Perinatol. 2006;30:81-8.

8. JPitcher JB, Riley AM, Doeltgen SH, Kurylowicz L, Joh C. Rothwell physiological evidence consistent with reduced neuroplasticity in human adolescents born preterm. J Neurosci. 2012;32(46):16410-6. https:// doi: 10.1523/JNEUROSCI.3079-12.2012

9. Johnson S, Evans TA, Draper ES, Field DS, Manktelow BN. Neurodevelopmental outcomes following late and moderate prematurity: a population-based cohort study. Arch Dis Child Fetal Neonatal Ed. 2015;100(4): F301-8. https:// doi: 10.1136/archdischild-2014-307684

10. Raju TN, Higgins RD, Stark AR, Leveno KJ. Optimizing Care and Outcome for Late Preterm Infants: A summary of the workshop sponsored by the National Insttitude of Child Health and Human Development. Pediatrics 2006;118(3):1207-14.

11. Ballard IL, Khory SC, Wrong L, Eilers-Wosman BL, Lipp R. New ballard score; Expenden to include extremely premature infants. J Pediatrics 1991;119:417-23.

12. Ovalı F. Intrauterine Growth Curves for Turkish Infants; Born Between 25 and 42 Weeks of Gestation.J Trop Ped 2003;49(6):381-3. https:// doi: 10.1093/tropej/49.6.381.

13. Gökçay G, Furman A, Neyzi O. Updated growth curves for Turkish children aged 15 days 60 months. Child Care Health Dev. 2008;34(4):454-63. https:// doi: 10.1111/j.1365-2214.2008.00813.x

14. Töllner U. Early diagnosis of septicemia in the newborn. Clinical studies and sepsis score. Eur J Pediatr. 1982;138(4):331-7. https:// DOI: 10.1007/bf00442511

15. Walsh MC, Kliegman RM. Necrotizing enterocolitis: treatment based on staging criteria. Pediatr Clin North Am 1986;33(1):179-201. https:// DOI: 10.1016/s0031-3955(16)34975-6

16. Papile LA, Munsick-Bruno G, Schaefer A. Relationship of cerebral intraventricular hemorrhage and early childhood neurologic handicaps. J Pediatr 1983;103(2):273-7. https:// DOI: 10.1016/s0022-3476(83)80366-7

17. Screening examination of premature infants for retinopathy of prematurity. Section on Ophthalmology 
American Academy of Pediatrics; American Academy of Ophthalmology; American Association for Pediatric Ophthalmology and Strabismus. Pediatrics. 2006;117(2):572-6.

18. Mc Kinlay CJ, Alsweiler JM, Ansell JM, et al. Neonatal glycemia and neurodevelopmental outcomes at two years. N Engl J Med. 2015;373(16):1507-18. https:// doi: 10.1056/NEJMoa1504909.

19. Çelikkiran S, Bozkurt H, Coşkun M. Denver developmental test findings and their relationship with sociodemographic variables in a large community sample of 0-4 year-old children. Noro Psikiyatr Ars. 2015;52(2): 180-4.

https:// doi: 10.5152/npa.2015.7230

20. William W Andrews, Suzanne P. Cliver, Fred Blasini,et al. Early preterm birth: association between in utero exposure to acute inflammation and severe neurodevelopmental disability at 6 years of age. Am J Obstet Gynecol. 2008;198(4):466.e1-466.e11. https:// doi: 10.1016/j.ajog.2007.12.031.

21. Kesiak M, Gulczynska E, Nowakoswka D, Wilczynski J. Influence of antenatal steroid therapy on newborn nervous system. Ginekol Pol. 2002;73(8):709-18.

22. Göçer C, Kavuncuoğlu S, Arslan G, Ertem I, Özbek S. Neurodevelopmental problems and factors affecting neurogical morbidity of very low birth weight prematüre infants. Turk Arch Ped. 2011;46:199-206.

23. Özsoy Koç Ö, Kavuncuoğlu S, Ramoğlu M, Aldemir E, Köprülü A, Eras Z. School performance and neurodevelopment of very low birth weight preterm infants: First report from Turkey J Child Neurol. 2016;31(2):170-6. https:// doi: 10.1177/0883073815587028

24. McGowan JE, Alderdice FA, et al. Impact of neonatal intensive care on late preterm infants; developmental outcomes at 3 years. Pediatrics. 2012;130(5):e110512.

https:// doi: 10.1542/peds.2012-0745.

25. Marjanneke de Jong, Marjolein Verhoeven, Carole A Lasham, Clemens B Meijssen, Anneloes L van Baar. behaviour and development in 24 month-old moderately preterm toddlers. Arch Dis Child. 2015;100(6):54853.

https:// doi: 10.1136/archdischild-2014-307016

26. Chaudhari S, Kulkarni S, Pajnigar F, Pandit AN, Deshmukh S. A Longitudinal follow of development of preterm infants. Indian Pediatr. 1991;28(8):873-80.

27. vanBaar AL, Vermaas J, Knots E, deKleine MJK, Soons SP. Functioning at school age of moderately preterm children born at 32 to 36 weeks gestational age. Pediatrics. 2009;124(1):251-7.

https:// doi: 10.1542/peds.2008-2315.

28. Lems W, Hopkins B.Mental and motor development in preterm infants the issue of corrected age. Early Hum Dev. 1993;34(1-2):113-23.

29. Lucas A, Morley R, Cole JT. Adverse neurodevelopmental outcomes of moderate neonatal hypoglycaemia. BMJ 1988;297:1304-8.

30. Robert Booy, Lidia Hristeva.Prospective surveliance of neonatal menengitidis. Arch Dis Child 1994;71:75-80.

31. Cooke RW. Perinatal and postnatal factors in very preterm infants and subsequent cognitive and motor abilities. Arch Dis Child Fetal Neonatal Ed. 2005;90(1):F60-3.

32. Vollmer B, Roth S, Baudin J, Stewart AL, Neville BG, Wyatt JS. Predictors of long term outcome in very preterm infants: Gestational age, versus neonatal cranial ultrasound. Pediatrics. 2003;112(5):1108-14. 